\title{
Job satisfaction among Occupational Therapists
}

\author{
Uvana Sewpersadh, BOT (UDW), PgDip.Hand Rehab (UKZN), MBA (UKZN) \\ Private practice
}

Thanalutchmy Lingah, BOT (UDW), MBA (Wales)

Lecturer, Discipline of Occupational Therapy, School of Health Sciences, UKZN

Pragashnie Govender, BOT (UDW), MOT (UKZN), PhD (UKZN)
Lecturer, Discipline of Occupational Therapy, School of Health Sciences, UKZN

\section{INTRODUCTION}

Job satisfaction is a well-known concept and is defined as the attitude of a worker towards his or her job, often expressed as a pleasurable response of liking and disliking the work itself, the rewards (pay, promotions, recognition) or the contexts (working conditions, colleagues)'.

Whilst there have been international studies investigating the level of job satisfaction of occupational therapists, there are currently no studies carried out to date in South Africa. From a perusal of some of the international studies ${ }^{2-5}$, it appears as though the major contributor to job dissatisfaction is poor working conditions with factors supporting job satisfaction including enjoyment experienced from teamwork, that is, working with other occupational therapists and colleagues from other health backgrounds, client interaction and interpersonal relationships with co-workers, work that is challenging and rewarding, autonomy, reasonable workload, high quality supervision, and equitable salaries and a sense of pride and achievement when therapeutic goals are achieved.

Anecdotal evidence from occupational therapists reveal that they appear to be dissatisfied with their jobs. This study was therefore positioned as a pilot study that may identify whether occupational therapists are satisfied with their jobs, but will also serve in creating a platform for further research and development in the professional discipline of occupational therapy.

\section{METHODS}

A cross-sectional survey design was utilised with a purposive sample of 95 occupational therapists working in various settings in the eThekwini district of KwaZulu-Natal based on a set of selection criteria. Surveys were distributed electronically, via post and physically to therapists in the district. Forty-nine questionnaires were returned for analysis reflecting a $51.5 \%$ response rate. The questionnaire comprised of two sections. Section A, was focussed on obtaining demographic information of the participants. Section B comprised a standardised questionnaire, the Job Satisfaction Survey (JSS) ${ }^{6}$. The $\mathrm{JSS}^{6}$ is a multidimensional instrument designed for use in human service organisations and is a 36 item, nine facet scale which assesses employee attitudes about their jobs. The nine facets or subscales include salary, promotion, supervision, fringe benefits, contingent rewards, operation procedures, co-workers, nature of work and communication. The Statistical Package for Social Scientists (SPSS) version 15 was used for analysis.

\section{RESULTS}

Public sector occupational therapists made up the greater number of respondents ( $n=33$ or $67.4 \%)$. Thirty point six percent $(n=15)$ of the respondents had been qualified for between 4-7 years with a majority of the respondents primary area of practice being in the paediatric field of occupational therapy ( $n=24$ or $49 \%)$. The majority of respondents earned a salary of between RI22 284 RI46 $684(n=19$ or $40.8 \%)$ at the time of the study. A majority of respondents did not possess post-graduate qualifications $(n=42$ or $83.67 \%$ ). Of the respondents that did hold post-graduate qualifications, a post-graduate diploma was identified as the most commonly held qualification ( $n=4$ or $8.16 \%)$. From the study, $55.1 \%(n=27)$ of occupational therapists revealed that they were in part-time private practice over weekends, over and above their normal work.

\section{Job Satisfaction}

The arithmetic mean and standard deviation were computed for the various dimensions measured by the JSS. The results are presented in Table I. The norms of the original Spector's Job Satisfaction Questionnaire are also presented for comparative purposes ${ }^{6}$.

Table I: Comparison of dimensions of job satisfaction norms ${ }^{6}$ against the sample of OTs

\begin{tabular}{|l|c|c|c|c|}
\hline JSS Dimensions & \multicolumn{2}{|c|}{$\begin{array}{c}\text { Occupational } \\
\text { Therapists }\end{array}$} & \multicolumn{2}{c|}{ JSS Norms $^{6}$} \\
\hline & $\begin{array}{c}\text { Mean } \\
\text { Standard } \\
\text { Deviation }\end{array}$ & Mean & $\begin{array}{c}\text { Standard } \\
\text { Deviation }\end{array}$ \\
\hline Pay & 12.43 & 1.65 & 11.6 & 2.3 \\
\hline Promotion & 14.00 & 1.31 & 11.7 & 1.9 \\
\hline Supervision & 14.00 & 0.00 & 18.7 & 1.9 \\
\hline Fringe benefits & 14.00 & 0.00 & 13.7 & 2.1 \\
\hline $\begin{array}{l}\text { Contingent } \\
\text { rewards }\end{array}$ & 14.06 & 3.31 & 13.5 & 2.0 \\
\hline $\begin{array}{l}\text { Operating } \\
\text { conditions }\end{array}$ & 14.90 & 1.60 & 13.3 & 1.9 \\
\hline Co-workers & 14.65 & 2.10 & 17.9 & 1.7 \\
\hline Nature of work & 15.35 & 2.64 & 18.8 & 2.2 \\
\hline Communication & 14.12 & 1.35 & 14.4 & 1.9 \\
\hline TOTAL SCORE & $\mathbf{I 2 6 . 2 4}$ & $\mathbf{6 . 7 7}$ & $\mathbf{I 3 3 . 5}$ & $\mathbf{I 2 . 7}$ \\
\hline
\end{tabular}

The results in Table I draws comparisons between the JSS norms and the results collected from the present sample. The results indicate that occupational therapists are most satisfied with the nature 
of their work (mean = I 5.35), followed by the operating conditions $($ mean $=14.90 ; S D=1.60)$ and their co-workers (mean $=14.65$; $S D=2.10)$. They are, however, less satisfied with promotional opportunities (mean $=14.00 ; S D=1.3 \mathrm{I}$ ) and least satisfied with the pay they receive $($ mean $=12.43 ; S D=1.65)$.

\section{Dissatisfaction versus Satisfaction}

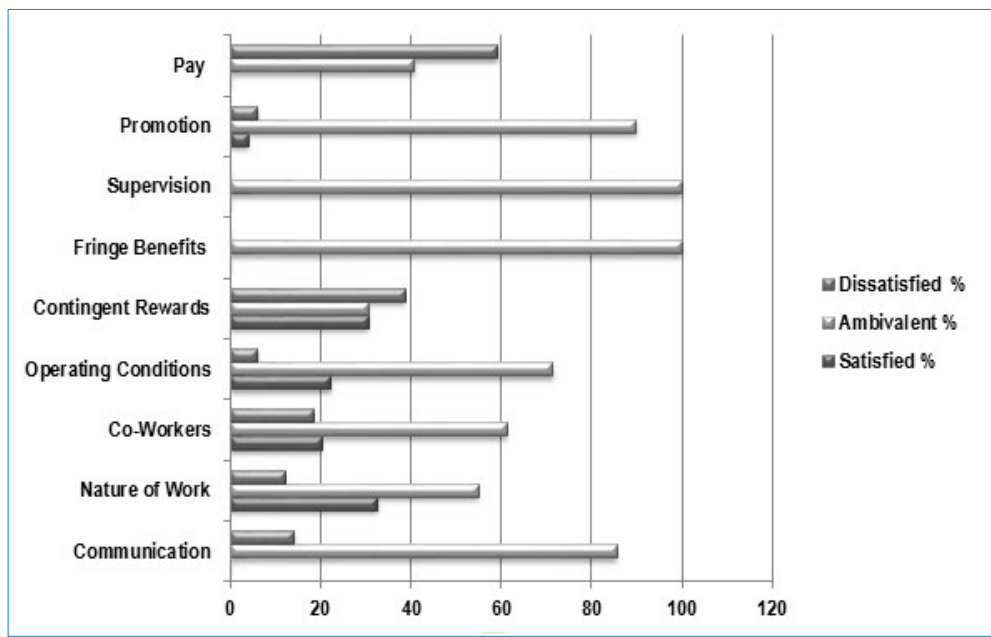

Figure I: Level of Job Satisfaction

Figure I shows the results of the cut scores of the JSS, reflecting the level of job satisfaction experienced by occupational therapists. Spector ${ }^{6}$ derived the following cut scores to represent dissatisfaction versus satisfaction, 36 to 108 for dissatisfaction, 44 to 216 for satisfaction, And between 108 and 144 for ambivalent. Figure I shows that the scale with the highest percentage of dissatisfaction was pay, and that with the highest level of satisfaction was nature of work. Overall, all participants were classified as ambivalent (unsure).

\section{Job Satisfaction and demographic variables}

No significant associations were found between demographic variables and overall job satisfaction.

\section{DISCUSSION}

This study sought to determine the level of job satisfaction in a cohort of occupational therapists within one district of KwaZuluNatal. The results suggest that overall, occupational therapists are unsure (ambivalent) of their level of job satisfaction. Occupational therapists appeared to experience the highest level of satisfaction with the nature of their work, operating conditions and working with co-workers, whilst pay (salary) was a major source of job dissatisfaction. The average salary level of occupational therapists in the sample was between RI22 84I to RI46 684. The results also indicated that $55.1 \%$ of occupational therapists were involved in part-time practice in addition to the full time work within the public sector. The reason for taking up part-time work was identified by all occupational therapists as being for the reward of additional income, which suggests dissatisfaction with their salary structures at the time. Moreover, occupational therapists reflected that the lack of promotional opportunities contributed significantly to their lack of job satisfaction. At the time of the study, clinical posts in the province spanned three tiers: grade I (newly qualified therapists to up to nine years of experience), grade two (minimum 10 years of experience) and grade three (minimum 20 years of experience). This suggested that clinical posts did not span many promotional levels, thereby inhibiting one's ability to progress professionally within the clinical field which in turn has implications for salary progression.

A number of reasons may have attributed to salary and promotional opportunities being inadequate for therapists. It may be apparent that the salary scales and structure within the public sector at the time was inadequate in meeting therapists' day to day living costs, with therapists therefore seeking external employment to supplement their income. Seeking better opportunities outside of the public sector may have been part of the attraction for therapists at the time. A recommendation would thus have been to revisit service conditions and salary structures of health care professionals within the public sector. Congruent with this, opportunities for promotions and upward mobility needs to be implemented to influence personal satisfaction for those therapists remaining in the public sector given that the nature of the work was a huge source of satisfaction.

An important factor to consider at this point was that this study was undertaken just prior to the moratorium passed by the KwaZulu-Natal provincial administration on private remunerative work ${ }^{7}$ and during the introduction of the occupation-specific (remuneration and careerprogression) dispensation (OSD) ${ }^{8}$. The introduction of OSD was in response to the increased need for a remuneration system that was to take into consideration the scarcity of skills, relevant experience including the supply and demand of practitioners. Against this backdrop of OSD, the Public Service Co-ordinating Bargaining Council (PSCBC) Resolution I of 2007 was created as an agreement on the salary increase and improvement in working conditions ${ }^{8}$. The allied health cluster (one of four) with 56 categories included professionals, assistants and technicians for occupational therapy, amidst other categories ${ }^{8}$. One of the objectives was to provide clear salary and career progression measures based on, amongst others, competence and performance and to reward the skills and professional competencies ${ }^{8}$.

Given these vital changes to the public sector, the situation may have changed with public sector therapists. A follow up study to determine levels of satisfaction may be useful in understanding the potential impact of these measures, namely, OSD and moratorium on private remunerative work.

\section{CONCLUSION AND RECOMMENDATIONS}

This study provides initial data on the level of job satisfaction in a small group of occupational therapists and may be used as a starting point to determine factors that enhance a positive work experience and satisfaction in the profession. It has emerged that pay and promotional opportunities appear to be the two dimensions of work that therapists are dissatisfied with. There has been advocacy for allied health professions, amongst others, with the introduction of OSD to respond to the pay and promotional issues that were of concern. As mentioned above, studies to investigate the impact and influence of these changes within the public sector may be useful in understanding whether occupational therapists indeed remain satisfied in their jobs.

On a micro-level, employing bodies may be encouraged to evaluate components of job satisfaction amongst occupational therapists to ensure that suitable career path opportunities are developed for them as part of the retention policy of the employing body. Perhaps there may also be a need for additional research to investigate the potential relationships and the effect these variables and other extraneous variables, such as role ambiguity, job level, contingent rewards and working conditions, may have on job satisfaction amongst occupational therapists and for measures to be put into place to address these issues.

\section{REFERENCES}

I. Vandenbos GR. APA dictionary of psychology. Washington, DC: American Psychological Association, 2007.

2. Davis GL \& Bordieri JE. Perceived autonomy and job satisfaction in occupational therapists. American Journal of Occupational Therapy, 1988, 42(9): 59I-595.

3. Hellickson L, Knapp D \& Ritter S. Comparison of Job satisfaction in occupational therapy settings. University of Wisconsin-La Crosse Journal of Undergraduate Research, 2000,3: 293-300.

4. Freda M. Retaining occupational therapists in rehabilitation settings: 
Influential factors. American Journal of Occupational Therapy, 1992,46: 240-245.

5. Madill HM, Macnab D, Brintnell ES, Stewin LL \& Fitzsimmons GW. High and low job satisfaction: some characteristics of two groups of occupational therapists. Canadian Journal of Occupational Therapy, 1987,54(22): 7I-78

6. Spector PE. Job satisfaction: Application, assessment, causes and consequences. Thousand Oaks: Califf: Sage Publications, 1997

7. Govender A. Provincial Policy Framework on Remunerative Work outside the Public Service. KwaZulu Natal Provincial Administration, 0I October 2009. <http://www.kznworks.gov.za/ LinkClick.aspx?link=Docs\%FProv+Policy+on+RWOPS.03 I 0. pdf\&tabid $=\mid 46 \&$ mid $=587>$ ( $\mid$ June 20I5).

8. Public Service Co-ordinating Bargaining Council (PSCBC). Resolution I of 2007. <www.pscbc.org.za/wp-content/uploads/ Resolution-I-of-2007.pdf >

\section{Corresponding Author}

Uvana Sewpersadh

uvanas@gmail.com 